\title{
12 THE IMPACT OF UBIQUITOUS COMPUTING TECHNOLOGIES ON BUSINESS PROCESS CHANGE AND MANAGEMENT: The Case of Singapore's National Library Board
}

\author{
Anand Ramchand \\ Paul Raj Devadoss \\ Shan L. Pan \\ Department of Information Systems \\ National University of Singapore \\ Singapore
}

\begin{abstract}
Ubiquitous computing technologies are reaching a stage of technical maturity that is enabling their application in everyday business environments. As organizations increasingly adopt these technologies, such as radio frequency identification (RFID), a deeper understanding of their impacts on business process management and design will reveal innovative opportunities for organizations to leverage upon in achieving their objectives. The case of RFID adoption at the National Library Board (NLB) reveals how the technology has enabled deskilling, modularity, and motility in business processes. As a result, NLB has enjoyed higher levels of efficiency, developed novel and differentiated services, and achieved greater customer satisfaction.
\end{abstract}

\section{INTRODUCTION}

The concept of ubiquitous computing (Weiser 1991) is the result of advanced developments in computing and communication technologies, coupled with their widespread adoption by individuals and organizations. The rapid diffusion of such technologies has profoundly altered the way computing has been utilized and exploited to make personal and work lives more effective and efficient. Computing and technological capabilities are no longer viewed from the depreciatory perspective of 
machines that simply perform tasks using a repository of custom software in isolated environments that users enter and leave. Instead, an increasingly popular and desired notion of computing is that of enabling integrated information-and application-enhanced physical spaces, with the perceptual capability to allow users to interact naturally with their information (Saha and Mukherjee 2003). This is achieved through the use of increasingly mobile and pervasive communication and computing devices. This notion forms the basic premise of ubiquitous (or "anytime, anyplace") computing: "an assemblage of interconnected technological elements that enable the mobility of computing and communication services" (Yoo and Lyytinen 2003, p. 2).

Ubiquitous computing technologies are reaching a stage of technical maturity that enables their application in everyday business and social environments (Fleisch 2001; Stanford 2002). Recent literature suggests ubiquitous computing technologies present considerable potential to significantly change how work is performed at organizational, team and individual levels in numerous ways (e.g., Davis 2002; Jessup and Robey 2002; Lyytinen and Yoo 2002; Lyytinen et al. 2004). The design of organizational business processes and the exploitation of information technologies constitute a recursive relationship, in which IT is a key enabler in transforming, as well as supporting, business processes (Davenport and Short 1990; Venkatraman 1994). With increasing intelligence and mobility, seamless integration into physical environments, and declining costs, the adoption and application of ubiquitous computing technologies by organizations are enabling substantially new and distinctive service options and business processes, and, consequently, creating a variety of impacts on organizations (Strassner and Schoch 2002).

The intent of this paper is two-fold. First, based on an exploratory study of the adoption of radio frequency identification (RFID) in Singapore's National Library Board's (NLB) as part of strategy-driven process changes, we provide empirically based insights into the strategic use of ubiquitous computing technologies in enabling innovative business processes, with particular regard to their impact on process owners and process design. Second, we highlight the enablers of such impacts and their implications on organizations. In the discourse of these issues, we discuss areas where future research may provide a deeper understanding of the effects of ubiquitous technologies in organizations.

\section{LITERATURE REVIEW}

Business processes, "logically related tasks performed to achieve a defined business outcome" (Davenport and Short 1990), typically consist of structure, inputs, outputs, internal or external customers, and owners (Al-Mashari and Zairi 2000; Davenport and Short 1990). Processes reflect how work is performed and can be strategically changed or redesigned to provide organizations with significant improvements. The role of IT has been shown to be fundamental and multifaceted in this endeavor (Attaran 2004), enabling and facilitating organizations in implementing radically improved processes, rather than merely automating current ones (Al-Mashari and Zairi 2000; Hammer 1990). Process change efforts, however, consist of a continuum of approaches and may not only be radical in nature, but may also be evolutionary and incremental (Stoddard and 
Jarvenpaa 1995). Such strategy-driven process change efforts are characterized by the transformation of organizational subsystems, such as people, IT, or coordination mechanisms, and aim to improve process outcomes (Kettinger et al. 1997).

RFIDs, an automatic identification technology, represent an enabler of emerging ubiquitous computing technologies and applications (Want et al. 1999), and have had strong impacts on business processes. In RFID systems, tags (small chips with antennas and information storage capabilities) are attached to and used to identify physical entities through radio waves using an RFID reader. RFIDs are significantly better than earlier auto-identification technologies as they do not require human intervention in the identification process, do not need line of sight between the reader and entities, can identify many entities simultaneously, and have larger data storage capacity (Stanford 2003; Strassner and Schoch 2002).

Due to the automated nature of data input into enterprise systems, RFIDs eliminate media breaks (the need for human intervention in transferring data from one medium to another), thus simplifying and accelerating business processes, reducing input and processing errors, and allowing organizations to achieve higher levels of data integration (Fleisch 2001). As a result, RFID systems bridge existing and cumbersome gaps between the transference of physical data into digital domains. RFIDs also provide opportunities to achieve significant process freedoms by removing more human intervention from business processes than previous technologies, as well as enabling greater information visibility throughout organizational supply chains (Angeles 2005). RFID systems have frequently been employed in supply chain and logistics tracking business processes to permit the automatic capture of product location and information, supplementing data input into organizational systems and allowing organizations to streamline their processes and minimize errors.

Effective process design should not be merely techno-centric; it requires a balanced socio-technical perspective (Markus and Robey 1995; Sarker and Lee 2002). Process change initiatives not only change the IT capabilities and infrastructure of the organization, but also the roles and responsibilities of organizational members and the structure of the organization itself. Process redesign efforts driven by traditional IT typically result in a need for greater ownership and direct responsibility over the operation of processes by process owners, as outmoded hierarchies are replaced with flattened, leaner structures and decentralized decision making (Cunningham and Finnegan 2004). Process owners are made completely responsible for and maintain complete authority over their processes, from their initial design to implementation and performance evaluation, as well as planning training efforts for front-line employees. Process owners also play a vital role in guiding the evolution and adaptation of the new processes, ensuring the outmoded methods do not resurface, managing process employees, and incrementally improving the process over time (Hammer and Stanton 1999). However, the ownership over cross-functional processes introduces significant operational burdens on senior managers, making the realization of true strategic effectiveness from newly implemented processes and their management difficult (Lee and Dale 1998).

As the adoption of nontraditional, ubiquitous computing technologies in organizations increases, a deeper and more detailed understanding of the consequences and opportunities afforded by such technologies on newly designed business processes and their management is necessary to bring about effective implementation and suitable practices for organizations. 


\section{RESEARCH METHOD}

An exploratory case study was conducted at the National Library Board (NLB) of Singapore, investigating the adoption of RFID technologies and the subsequent implementation of a first-of-its-kind system. Data was collected in September 2003 from a total of 43 semi-structured interviews with staff from various divisions of NLB. As the investigation studied the adoption and implementation period from 1996 to 2003, interviewees were drawn from a wide variety of business functions and managerial levels, as well as with varying seniority of service (ranging from 6 months to 32 years). The open-ended interviews allowed the researchers to gather data on a wide variety of issues and perspectives from interviewees. Interviews were recorded and subsequently transcribed verbatim and supplemented with field observations.

Further data for the study was drawn from interviews with NLB's RFID-technology partner, ST Logitrack, in order to gather insights into the technical details of the technology adoption, as well as useful secondary opinions on the use of RFIDs in NLB. Data was also gathered through various documents such as press releases, internal reports, internal magazine write-ups, other research reports, and popular press articles. Such data supplemented information gathered on scope of projects, objectives, achievements and issues handled during the various stages of adoption at NLB. Further data was also gathered through personal observations at NLB's libraries and office premises during visits to 13 different libraries, NLB's headquarters, and its supply center.

\section{CASE DESCRIPTION}

Based on a vision drawn up in consultation with an extensive cross section of the society to expand the learning capacity of the nation, the Singapore government formed the National Library Board in 1995 to transform Singapore's library services in the information age. In its current form, NLB provides services for 70 libraries in Singapore including 39 national public libraries, of which 3 are large regional libraries, 18 community libraries, and 18 children's libraries.

NLB set about the task of increasing its annual book loans of about 10 million in 1994. It began with an extensive business process reengineering exercise in 1996 targeting the consolidation and optimization of business processes that were concurrent, identifying the need for radical solutions due to mismatches between existing capabilities and targets set by NLB's vision. This exercise also presented the organization with a complete idea on all processes and involved key process owners in the development of performance targets. As the CEO of NLB noted,

We knew we had to start right now because we had such high targets set for us through Library 2000 for the following years. If we didn't start now [1996], we'd never reach there!

Several technology solutions were considered potentially useful, including the implementation of self service stations for library services and the introduction of more services that delight the customers. In the words of the CEO, 
We started to look at three things that people didn't like in our libraries... long queues, time to provide new items and serving open-ended enquiries.

Existing barcode systems were difficult to use for library patrons since they required aligning the book physically with the reader in order to be read by the machine. The manager of the Innovation and Services Department (ISD) reported,

You might wonder what's so hard in aligning the book, but considering the number of people who require assistance, the average time for a loan shoots up rendering it relatively inefficient.

Also, book returns were handled manually despite book return chutes, located at library entrances, through which users could drop off books anytime of the day. However, this system didn't work well since it left users waiting for the staff to update the system before they could borrow again.

Scouting for a better technology to handle the books, NLB identified RFID as a potential technology. In Singapore, Singapore Technologies Logistics and Singapore Technologies Electronics had explored RFID applications for logistics operations. Along with NLB, the three partners developed a prototype demonstrated in November 1997. As a project manager recalled,

When the book with RFID chip was dropped down a reader-embedded container, the reader successfully recognized the drop! There began the long journey toward its application in libraries,

\subsection{Deploying RFIDs}

A passive RFID chip embedded in the spine of the book (currently, with the availability of smaller chips, it is pasted on the last page of the book) identifies a book to scanners in close proximity. All library items are tagged with an RFID chip, containing information identifying the book, the library branch, and rack numbers where the book is shelved. In a book loan or return process, the data would be used together with the library user's identity to manage the library user's loan information. The data is initially stored in a local server, which operates with a backup and is then synchronized with the centralized data servers.

In the months following the demonstration, ST Electronics developed a prototype for a new library that NLB was renovating at Bukit Batok Community Library. The manager of ISD noted,

In those 9 months from early 1998 to November 1998 to when the Bukit Batok Community Library was opened after renovation, we worked on designing the system, developing the software, the interfaces...the whole package. I can say that we were the first fully functional library with over 100,000 items on loan using RFID. 
A manager from NLB summed up the library user reaction to the new technology.

There's a sense of amazement. I can put the book in any direction... it still works. We approached this library as a prototype, it worked great, the public loved it and that is why it is still there!

Self service book loan counters were designed with a simple interface with options for all four official languages (English, Chinese, Malay, and Tamil). Users log into the system by placing their identity cards into the machine and place each book they wish to check out on the reader. The screen confirms by displaying the books checked out and the account status. A book return chutes were equipped with a scanner to log returned books instantly. At the book drop, the user drops the book through a chute, where RFID scanners update the systems on users' book loans instantaneously. The book drop service is located at the entrance of a library, in order to make the service available 24 hours a day. Books can now be returned at any of NLB's libraries through book drop counters, anytime of the day. A manager at NLB stated,

The technology can support many books being dropped in at a time, but we'd rather that the users drop one at a time since that will help our users be aware of the books they drop in...this is a human constraint.

The technology had to be reined in, to make it easier for the users and save NLB the task of handling too many lost items from users. A library officer also noted this about users:

Sometimes [they] drop in their own books though it can only accept one book at a time.... Or they even drop other library books like school library books or school text books! We then take care of such books through "lost and found" during sorting and shelving.

Since the loan information was instantly updated to their library user's record, it encouraged more loans by library users. As a manager commented,

With the old system, they sometimes ask why their account is not credited when they've already returned a book... and our staff would have to retrieve it from the overnight pile of books and speed up this users return.

A librarian summed it up as follows while commenting on the processes in sorting:

With the RFID systems in place, the sorting process is a breeze because this computer [attached to the scanner] even shows the shelf number for the book.

The efficiency of loaning books and returning them at book drops at any library improved user expericnce at libraries, helping in the growth of book loans at NLB. The organization was learning from the deployment of the system, observing it in operation and working on improving at the next implementation within a year. The whole implementation was again piloted at the next library in 1999. Two more libraries were 
piloted before the systems were functioning to the satisfaction of NLB. NLB then invited global tenders for implementing the system across all its libraries in 2000 . Singapore Technologies Logitrack, a joint venture by ST Electronics and ST Logistics, was awarded the tender and has since rolled out the RFID systems in all NLB libraries in Singapore. The entire process was completed in April of 2002. The success of the technology during pilot testing prompted other libraries to start requesting its implementation. As the project manager reported,

When the other libraries saw what we could do with RFID, they too wanted it. RFID was helping them achieve targets which would otherwise consume tremendous resources.

With increasing adoption of IT, awareness of its potential was recognized and accepted by users. The CIO added,

Now we had the pleasant problem of managing this demand.... We achieved our targets without retrenching any staff. Our retraining was focused on service quality, rather than technology since it was easy enough to use. To the library users, we have given a better service quality. In face to the library users, there is no need to even talk to our staff, but if they need to, our staffs have more time to do so!

\subsection{Impacts of IT at NLB}

The immediate objective of the organization in adopting RFID was accomplished by removing queues, delivering better service quality, and giving employees more time to do value added tasks. Further, innovation of new services was possible at libraries. According to the CEO,

The introduction of this technology... eliminated the queues; it eliminated the staff from the mundane work of having to stand there to attend to the customers. Now the customers can just go to the machine and check it out and our staff can do some other value-added work. Librarians are not there just to shelve books or stamp books; they are there to help you find information, which is higher value-added work.

With the introduction of IT, training was necessary in using such technologies. Also, with the savings in time spent at counters, staff were retrained to do greater value-added tasks. The CIO noted,

IT helped relieve mundane work. Staff are then trained to do more productive work in the back room or trained to become professional librarians where they help to organize information, help to select books, catalogue books, and they get to read what's the latest in the publishing industry. That adds to their intellect. So that's how staff would accept: "Yes, IT helps me in that." 
To the staff, the new systems literally liberated them from the loan counters. They now had more time to devote to improving services. A librarian noted that,

With the new systems, we now have more time to walk around the library answering queries from users instead of being tied to a desk. Our job satisfaction is driven by our ability to quickly answer user queries satisfactorily.

To manage book returns, NLB has an operations room behind the book return chutes where books are sorted. Returned books are sorted by shelf numbers or prepared for pickup by the postal service for delivery to other branches. A computer displays the shelf code encoded in the RFID chip in order to simplify the sorting process. A library officer demonstrating the process noted,

This system makes it easy to sort out the books and recognize their shelves.

Books are then carted off for shelving. The staff requested a color coded label on the spine indicating the collections to which a particular book belongs. This coding is uniform across all NLB libraries, and helps staff visually pick out incorrectly shelved books. Explaining the request by the librarians, the project manager noted,

The library staff gave us feedback that it was difficult to pick out a wrongly shelved book among all these books. So we accepted their feedback and put a label on the spine of the book.

Growing loans meant an increasing number of returns, thus placing a heavy burden on the shelving staff. An older staff involved in the shelving process commented,

This is a tedious process, returning books to the shelves all day! Especially during school vacations, the volume increases a lot. I wish this could be automated. It 's a hard thing to do all day... but it can't be automated, putting books to open shelves. It can only be done with closed shelves.

NLB employs part-time employees who help the staff with shelving. This strategy helps NLB carve the tedious work process into smaller, manageable schedules sourced to the part-time staff. In addition, several community programs bring in volunteers to help shelve books. Such programs also benefit NLB by helping them reach out to the community and engage them in a daily work process.

One of the junior staff, who has gone from "stamping books all day, " commented,

If I can answer a user's query well, then I am most satisfied with my job...we now have plenty of resources to do just that.

The management recognized the fact that some staff were unwilling to take the step into the future that the introduction of RFID systems heralded, namely greater use of IT in daily work routines. The management took into consideration the other events that were happening in the organization to understand the mixed feeling toward the introduction 
of the RFID systems. The management reacted appropriately, which the CEO summarized as follows:

We had so many things changing...the front office with the RFID systems...our back office with our HR FIS systems, and there was an overlap for about three years. It was a huge strain on the organization and naturally people were stressed. This is when we had to show patience, trust, and give time.

The top management engaged the staff in a dialogue and conveyed the message that these technologies were meant to help increase productivity. Commenting on the organization after the formation of NLB, the CIO noted,

When a new management introduces something...staffs worry if their job is safe. So we introduced tea talks, when the CEO was in direct touch with staff, explaining the objectives and allaying their fears.

To help staff cope with the changed environment in the organization, NLB provided training sessions, opportunities for skill development, and redeployment of some staff into other jobs.

With increasing adoption of RFID technologies at more branches, book loans were growing annually at NLB in addition to annual library user visits to the branches. The increased productivity was managed with retrained staff from other functions that had become redundant due to the introduction of IT. As the RFID technologies were adopted at each new library with incremental services being automated, less staff were needed to man the library. NLB countered this by increasing the responsibilities of lower rank staff to the extent that the first fully self-service DIY (do it yourself) styled library was launched with just one Systems Library Officer and one concierge who manage approximately 2,000 loans a day. Using a call center, NLB now provides support for user queries at libraries through its interactive Cybrarian kiosk. Users can see directions and demos of services while consulting a library call center staff.

NLB is now equipped to quickly deploy a loaning service even at remote community events using a virtual private network, thus taking the library to the people. One library manager commented,

It is now much more efficient... we used to write down the call numbers and then key them in later, which was error prone and slow.

The RFID-tagging of its collections has also drastically reduced the time spent in stocktaking of collections. None of the libraries now close for stocktaking, and the entire exercise at a library is completed overnight, except for the anomalies in reports which are followed up later. NLB constantly strives to identify potential business problems and find a solution that addresses a set of related processes. The CEO summed up the approach as

An optimized, automated solution to an immediate problem is our objective. 


\section{FINDINGS AND IMPLICATIONS}

The adoption of RFIDs by NLB demonstrates the efficacy of ubiquitous computing technologies in providing organizations with radical and novel approaches to solving traditional business problems using nontraditional and modern technologies. Permeating this usage are interesting insights and new perspectives into the impact of these technologies on transforming the management and design of business processes, namely, by enabling deskilling, modularity, and motility in business processes.

\subsection{Process Deskilling}

Prior to the RFID-tagging, customers experienced prolonged waiting times for services, caused both by physical and information delays. For instance, when returning an item, customers had to queue up at counters for service (physical delay), and subsequently wait for their loan records to be updated (information delay). Similarly, NLB had to update records manually (information delay) and proceed to shelve returned items for future loans (physical delay).

The initial implementation of book return chutes succeeded in dissociating the information and physical delays of the processes from the customer's perspective. While the system meant customers need not incur any waiting time to manually return loaned items, the updating of customer records was still manually performed, failing to remove haunting delays in service from NLB's back-office perspective.

With the adoption of RFIDs, NLB was able to further deskill the processes of loaning and returning simplifying them significantly enough to be performed through the use of RFID technology. When loaned items were automatically scanned at the book return chute, NLB membership records were instantaneously updated, eliminating all information delays in the process. This new capability was enabled by the embedded and communicative nature of the RFID tags in each book, which allowed the physical books to informate (Zuboff 1988) NLB systems without the need for human intercession, eliminating the media breaks inherent in the regular process. The calm nature of such ubiquitous technologies (Weiser 1991) makes it possible to minimize human interaction and control over the technology while it performs its tasks invisibly, making only its outcome noticeable (Want 2004).

The deskilling of the process had implications on the existing staff of the library. The removal of human intervention from the process led to the deskilling (Burris 1998) of many staff. Where librarians previously were needed to engage with customers, facilitate the acceptance of loan items, and update systems, these processes were now, through the use of embedded RFIDs, technology-enabled. NLB's employment of volunteers and part-time staff to carry out manual reshelving tasks meant that full-time librarians could be upskilled (Burris 1998) to solely perform other back-office and service-oriented tasks. As a result, NLB enjoyed significant savings in terms of human resource costs and time incurred to provide higher quality levels of service. 


\subsection{Process Modularity}

In addition to deskilling, the RFID system enabled the modularization of processes (Sanchez 1997) by moving input and output information dependencies to the interface of the customers with the technology. In modular process architectures, components of processes are standardized and can be reused for the creation of different functionalities and levels of performance (Sanchez 1997).

Prior to the RFID-tagging, reducing waiting times for services offered to customers involved the spawning of multiple, concurrent instances of those processes, and incurred the necessary resources for their deployment. For instance, in order to lower waiting times, NLB would deploy more staff at manual service counters. Such instances of service processes not only entailed increasing utilization of resources, but also increased the managerial monitoring and control efforts of process owners, who mediated and oversaw the activities of process employees.

With the RFID-enabled processes, not only were employees deskilled from the process, but process owners could focus on evaluating and improving the process from an abstraction created through the use of the technology (Zuboff 1988). The uniformity of the technology-enabled process allowed it to be replicated, based on this abstraction, numerous times and in various locations within and across libraries with little or no additional management or control activities by process owners. The inherent responsibilities of process owners were, therefore, assuaged and subsequently refocused, as they could focus on the activities of process evaluation and improvement, rather than process control and training, while being able to deploy and reuse the process effectively and efficiently to meet organizational objectives. As a result, the organizational capability to fully realize the efficiency gains from the new process are increased (Sanchez 1997).

The ubiquitous technology enabled such modularity by simplifying the process to a reduced, technology-enabled form, without the loss of information requirements, while embedding coordination between process functions (Sanchez 1997). Subsequent to deskilling the process, its initiation and dependencies were refocused onto the interface with the customer, rather than the intervention of NLB employees throughout its execution. Such process modularity further enabled the creation of new and novel services with greater ease. Being able to instantiate their RFID-enabled processes with little effort was vital in facilitating the creation of the self-serviced DIY library, manned by only two NLB staff. Furthermore, the capability to manage the process from an abstraction frees process owners to not only focus their efforts on process improvement, but also to combine efforts across core processes to deterministically seek gains from convergence, commonality, and overlaps, allowing organizations to truly enjoy the benefits of a process-oriented view of the organization.

\subsection{Process Motility}

The ability to adapt and duplicate processes easily in new, ad hoc and spontaneous situations at NLB is a result of the technology-enabled deskilling and process modularity achieved through the use of the RFID system. Process motility here refers to the 
flexibility to reuse modular processes innovatively to provide new services and functionalities in diverse contexts and locations. This view of processes looks beyond reconfiguring unbundled and independent process modules into new processes, and instead suggests that by enabling a supportive and coordinated IT architecture, ubiquitous technologies facilitate the relocation and reapplication of processes outside the firm's traditional location and context without a loss in process quality and functionality.

NLB sought advantages from the technology-enabled simplification of its processes, as well as their easy reproducibility and unmanned operations, to frequently provide services at ad hoc locations for short periods of time and during special events held at remote locations. Processes were motile as they could be quickly and easily implemented at locations previously inaccessible due to the cumbersome technical and human requirements of capturing data effectively and with minimal errors while at these locations. With the use of the RFID technology, however, tag readers could easily be set up so that self-service loan return counters could easily be deployed, thus permitting customers to access library services at locations previously unavailable.

The adoption of the ubiquitous technologies to enable process motility eliminated the spatial dependence of NLB's services. Traditional approaches, such as using book chutes at the libraries themselves, only managed to provide customers with the ability to access library returns services at any time, removing temporal restrictions on such services. The capability of process motility enabled by the RFID systems, however, facilitated the creation of novel services to bridge the spatial restrictions of service provision as well, allowing NLB to flexibly break through the notion that its services were only available at fixed locations, bringing its services closer to customers.

\section{CONCLUSION}

The newly implemented processes at NLB enabled by RFID technologies demonstrate how ubiquitous computing enables the deskilling, modularity, and motility of processes, signifying greater flexibility from organizational processes and their easier management. As a result of their adoption and usage, organizations stand to gain tremendous business value from the use of ubiquitous technologies such as RFIDs, including automation and information operations savings in terms of human resources, throughput, and operational flexibility, as well as transformational advantages such as the ability to create differentiated and innovative services across spatial and time dimensions previously inaccessible to the use of traditional technologies in processes. Furthermore, the process owner activities of controlling, monitoring, and managing processes and training staff are subsequently lightened, potentially enabling process owners to exert more effort on achieving holistic and strategic cross-process advantages for the organization to truly enjoy the benefits of newly designed, technology-enabled processes.

Further research is needed, however, to gain a deeper understanding of the impacts of such ubiquitous technologies on organizational processes. In particular, investigations into how organizations should rethink their approach and technology considerations in process change initiatives to fully exploit the advantages enabled and driven 
by ubiquitous technologies needs to be carried out. While customer-focused process redesign is a primary guideline, the development and deployment of new services and process efficiency gains enabled by the technologies can be underestimated. Organizations need to be imaginative and creative not only in their process change efforts, but also in their consideration of future capabilities enabled by ubiquitous computing technologies.

\section{REFERENCES}

Al-Mashari, M., and Zairi, M. "Revisiting BPR: A Holistic Review of Practice and Development," Business Process Management Journal (16:1), 2000, pp. 10-42.

Angeles, R. "RFID Technologies: Supply-Chain Applications and Implementation Issues," Information Systems Management, Winter 2005, pp. 51-65.

Attaran, M. "Exploring the Relationship Between Information Technology and Business Process Reengineering," Information and Management (41), 2004, pp. 585-596.

Burris, B. "Computerization in the Workplace," Annual Review of Sociology (24), 1998, pp. 141 157.

Cunningham, J., and Finnegan, P. "Process Improvement (PI) Programs and Information Systems: A Cross-Case Analysis of Impact," Journal of Information Technology (19), 2004, pp. 59-70.

Davenport, T., and Short, J. "The New Industrial Engineering: Information Technology and Business Process Redesign," Sloan Management Review (31:4), 1990, pp. 11-27.

Davis, G. B. "Anytime/Anyplace Computing and the Future of Knowledge Work," Communications of the ACM (45:12), 2002, pp. 67-73.

Fleisch, E. "Business Perspectives on Ubiquitous Computing," M-Lab Working Paper No. 4, University of St. Gallen, 2001.

Hammer, M. "Re-engineering Work: Don't Automate, Obliterate," Harvard Business Review (68:4), July/August 1990, pp. 104-112.

Hammer, M., and Stanton, S. "How Process Enterprises Really Work," Harvard Business Review (77), November/December 1999, pp. 108-118.

Jessup, L., and Robey, D. "The Relevance of Social Issues in Ubiquitous Computing Environments," Communications of the ACM (45:2), 2002, pp. 88-91.

Kettinger, W., Teng, J., and Guha, S. "Business Process Change: A Study of Methodologies, Techniques, and Tools," MIS Quarterly (21:1), 1997, pp. 55-80.

Lee, R. G., and Dale, B. G. "Business Process Management: A Review and Evaluation," Business Process Management Journal (4:3), 1998, pp. pp. 214-225.

Lyytinen, K., and Yoo, Y. "Research Commentary: The Next Wave of Nomadic Computing," Information Systems Research (13:4), 2002, pp. 377-388.

Lyytinen, K., Yoo, Y., Varshey, U., Ackerman, M. S., Davis, G., Avital, M., Robey, D., Sawyer, S., and Sorenson, C. "Surfing the Next Wave: Design and Implementation Challenges of Ubiquitous Computing Environments," Communications of the AIS (13), 2004, pp. 697-716.

Markus, M. L., and Robey, D. "Business Process Reengineering and the Role of Information Systems Professionals," in Business Process Change: Reengineering Concepts, Methods and Technologies V. Grover and W. J. Kettinger (Eds.), Harrisburg, PA: Idea Group Publishing, 1995, pp. 591-611.

Saha, D., and Mukherjee, A. "Pervasive Computing: A Paradigm for the $21^{\text {st }}$ Century," IEEE Computer, March 2003, pp. 25-31.

Sanchez, R. "Preparing for an Uncertain Future: Managing Organizations for Strategic Flexibility,"International Studies of Management and Organization (27:2), 1997, pp. 71-94. 
Sarker, S., and Lee, A. S. "Using a Positivist Case Research Methodology to Test Three Competing Theories-in-Use of Business Process Redesign," Journal of the Association for Information Systems (2:7), 2002, pp. 1-72.

Stanford, V. "Pervasive Computing Goes the Last Hundred Feet with RFID Systems," IEEE Pervasive Computing, April-June 2003, pp. 9-14.

Stanford, V. "Pervasive Computing Goes to Work: Interfacing to the Enterprise," IEEE Pervasive Computing, July-September 2002, pp. 6-12.

Stoddard, D., and Jarvenpaa, S. "Business Process Reengineering: Tactics for Managing Radical Change," Journal of Management Information Systems (12:1), 1995, pp. 81-108.

Strassner, M., and Schoch, T. "Today's Impact of Ubiquitous Computing on Business Processes," in Proceedings of the First International Conference on Pervasive Computing (Pervasive 2002), Short Paper Proceedings, Zurich, August 26-28, 2002, pp. 62-74.

Venkatraman, N. "IT-Enabled Business Transformation: From Automation to Business Scope Redefinition," Sloan Management Review (35:2), Winter 1994, pp. 73-87.

Want, R. "RFID: A Key to Automating Everything," Scientific American, January 2004, pp. 5665.

Want, R., Fishkin, K., Gujar, A., and Harrison, B. "Bridging Physical and Virtual Worlds with Electronic Tags," in Proceedings of the ACM Conference on Human Factors in Computing Systems, Pittsburgh, May 15-20, 1999, pp. 370-377.

Weiser, M. "The Computer for the $21^{\text {st }}$ Century," Scientific American, September 1991, pp. 94104; reprint: IEEE Pervasive Computing, January-March 2002, pp. 19-25.

Yoo, Y., and Lyytinen, K. "Measuring the Consequences of Ubiquitous Computing in Networked Organizations," Sprouts: Working Papers on Information Environments, Systems and Organizations (3), Summer, 2003 (available online at http://weatherhead. cwru.edu/sprouts/2003/030309.pdf).

Zuboff, S. In The Age of the Smart Machine: The Future of Work and Power, New York: Basic Books, 1988.

\section{ABOUT THE AUTHORS}

Anand Ramchand is a doctoral student with the Department of Information Systems, School of Computing, National University of Singapore. His research interests include ubiquitous and pervasive computing environments and the management of organizational knowledge. He can be reached by e-mail at ANAND@comp.nus.edu.sg.

Paul Raj Devadoss is a doctoral candidate with the Department of Information Systems, School of Computing, National University of Singapore. His research interests include egovernments, enterprise systems, IT use, and metastructurational activities in organizations. He can be reached by e-mail at PAULD@comp.nus.edu.sg.

Shan Ling Pan is the coordinator of Knowledge Management Laboratory in the Department of Information Systems of School of Computing at the National University of Singapore (NUS). Dr. Pan's research work has been published in IEEE Transactions on Engineering Management, Journal of the American Society for Information Systems and Technology, IEEE Transactions on Systems, Man, and Cybernetics, IEEE Transactions on Information Technology in Biomedicine, Journal of the Academy of Marketing Studies, Communications of ACM, Information and Organization, Journal of Strategic Information Systems, Journal of Organizational Computing and Electronic Commerce, European Journal of Operational Research, European Journal of Information Systems, and Decision Support Systems. He can be reached by e-mail at PANSL@ comp.nus.edu.sg. 